\title{
Decision making in mental health team meetings
}

\begin{abstract}
Background: Single point of access meetings represent a critical juncture in the lives of mental health clients. The decision-making process undertaken by mental health professionals during this time is therefore crucial.

Method: Glaserian grounded theory, with observations and interviews through theoretical sampling, was used to investigate the decision making of attendees.

Findings: A basic social process named handling role boundaries emerged, consisting of four phases: recognising, positioning, weighing up and balancing.

Conclusion: Handling role boundaries is an innovative, sociological theory that allows conceptual understanding to show how personality traits contribute to the discussions and decisions, as well as professional roles. These need to be managed effectively to make decisions in a limited time frame. Handling role boundaries explains how this is done in a local mental health trust.
\end{abstract}

Keywords: mental health, multidisciplinary team meetings, role boundaries

\section{Introduction}

This article describes a sociological study investigating a critical juncture in a client's pathway through local mental health services: the single point of access (SPA) meeting. Clients are absent from this meeting; it is for people with decision-making responsibilities. A Glaserian grounded theory approach to data collection and analysis (Glaser and Strauss 1967, Glaser 1978) has demonstrated that contributions to this decision-making process reflect something other than the person's professional capacities. This finding is revealing given the conventional focus on a multidisciplinary membership of such meetings. The identified grounded theory, named 'handling role boundaries', reflects the dynamics between identity, roles and interaction in decision making. It makes unprecedented sense of a complex and crucial process and explains how people working in a multidisciplinary mental health team work together effectively to triage and direct clients to perceived appropriate services and interventions. 


\section{Background}

SPA meetings have been set up in a local NHS trust to deal with incoming GP referrals based on meetings with clients who may have mental health problems. The referrals are written as letters to the appropriate community mental health team (CMHT). The letters are checked and triaged by a CMHT duty worker pre-meeting, and those that are deemed appropriate for discussion are processed and kept for the next SPA meeting. Clients' case notes are requested and may be discussed along with the GP letters at the meeting.

The SPA meetings occur in seven sites provided for by the trust and are held at least once a week. The length of the meetings is variable, as are the number of attendees. However, generally they are attended by CMHT members; for example, nurses, consultant psychiatrists, social workers, occupational therapists, and representatives from more specialist services, such as early intervention in psychosis, assertive outreach, improving access to psychological therapies (IAPT) and the crisis resolution home treatment team. Specialist services are those that cater for specific mental healthrelated needs. An administrative staff member also attends SPA meetings to distribute the letters and make notes. All meetings follow a similar general structure in which referral letters are read out by one attendee before discussion is invited from other attendees. Case notes may be consulted and all members must make a recordable decision about that client before the meeting ends. The decision is noted by administrative staff and later entered into the trust computer system. These decisions then contribute to the client's future experience with mental health services.

The organisation and procedure of SPA meetings have evolved in response to the changing context and dominant perspectives inherent in society. One strand of argument from sociology is that people are labelled as having mental health problems because they depart from social norms of society and are therefore deviants (Becker 1963, Erikson 1966, Eaton 2001, Giddens 2009). Subscribing to this understanding, SPA meetings, as part of mental health services, can then be seen as a strategy for dealing with the range of behaviours that are encompassed under the heading of 'mental health problems'. The plethora of services and teams with different organisational backgrounds and philosophies need to be represented in the SPA environment when decisions are to be made about potential clients, and SPA meeting attendees need to embrace the notion of multidisciplinary team working. The SPA procedure has had to ensure that it deals 
with the reported difficulties faced by GPs in managing mental health problems (Lucas et al 2005, Read 2005) and operate in an environment that supports the risk assessment practice that society has become accustomed to (Beck 1992, Rogers and Pilgrim 2005, Hewitt 2008, Turner and Colombo 2008).

Conceptualisation through an emerging grounded theory is important in this area because the result of decision making by SPA meeting attendees has a direct effect on clients - it influences what happens to them in terms of their interaction with mental health services. This often comes down to whether they will access specialist mental health services or not. The presentation of a grounded theory as a set of integrated concepts is often easier to understand than descriptive analysis. Theoretical knowledge of a process can be enlightening for people as it offers a way of capturing their experiences that has not been provided before (Artinian 1998, Artinian and West 2009). In the context of this study, this might allow SPA meeting attendees to identify what works well in their decision making, and what can be improved. This can have a significant effect on the clients receiving these mental health services.

\section{Method}

The SPA meetings were investigated using Glaserian grounded theory (Glaser 1978) and drawing on Glaser and proponents' directives (Artinian and West 2009). The main forms of data collection were observation and semi-structured interviews. A guiding research question was identified as: 'What is the nature of business and interactions around decision making within SPA meetings?' However, grounded theory also has a prominent methodological aim: to identify participants' problems and discover how they solve them (Glaser 1998, Artinian and West 2009). Such problems and solutions cannot be known before entering the field. So while the research question can guide the overall study, the emerging theory needs to be prioritised and, therefore, the guiding research question was kept broad.

In the grounded theory lexicon, identifying participants' problems is known as discovering their 'main concern' (Glaser and Strauss 1967, Glaser 1978, Cone and Artinian 2009, Giske and Artinian 2009). The main concern is a variable that motivates participants' behaviour. Such behaviour is carried out to resolve this main concern. To use a simplistic analogy, the main concern of a football coach could be the need for his 
or her team to win a football match. This may motivate behaviour such as strategic planning, including allocating players to the best possible playing positions to ensure that they win the match (thus resolving their concern). Behaviour is defined as ways of acting and conducting oneself (Oxford Dictionaries 2015) and can thus encompass verbal and non-verbal action.

The grounded theory researcher needs to allow participants themselves to reveal what their main concern is. In this study, this opportunity was given through data collection methods: observation and interviews. The main concern for SPA meeting participants was revealed to be the need to work together to make a decision about clients in the meeting. This was discovered by observing the agenda and routine that was made explicit throughout the meetings. All meetings had the same basic structure: a list of clients was presented through letters and case notes, a discussion ensued, and a decision was recorded for each client.

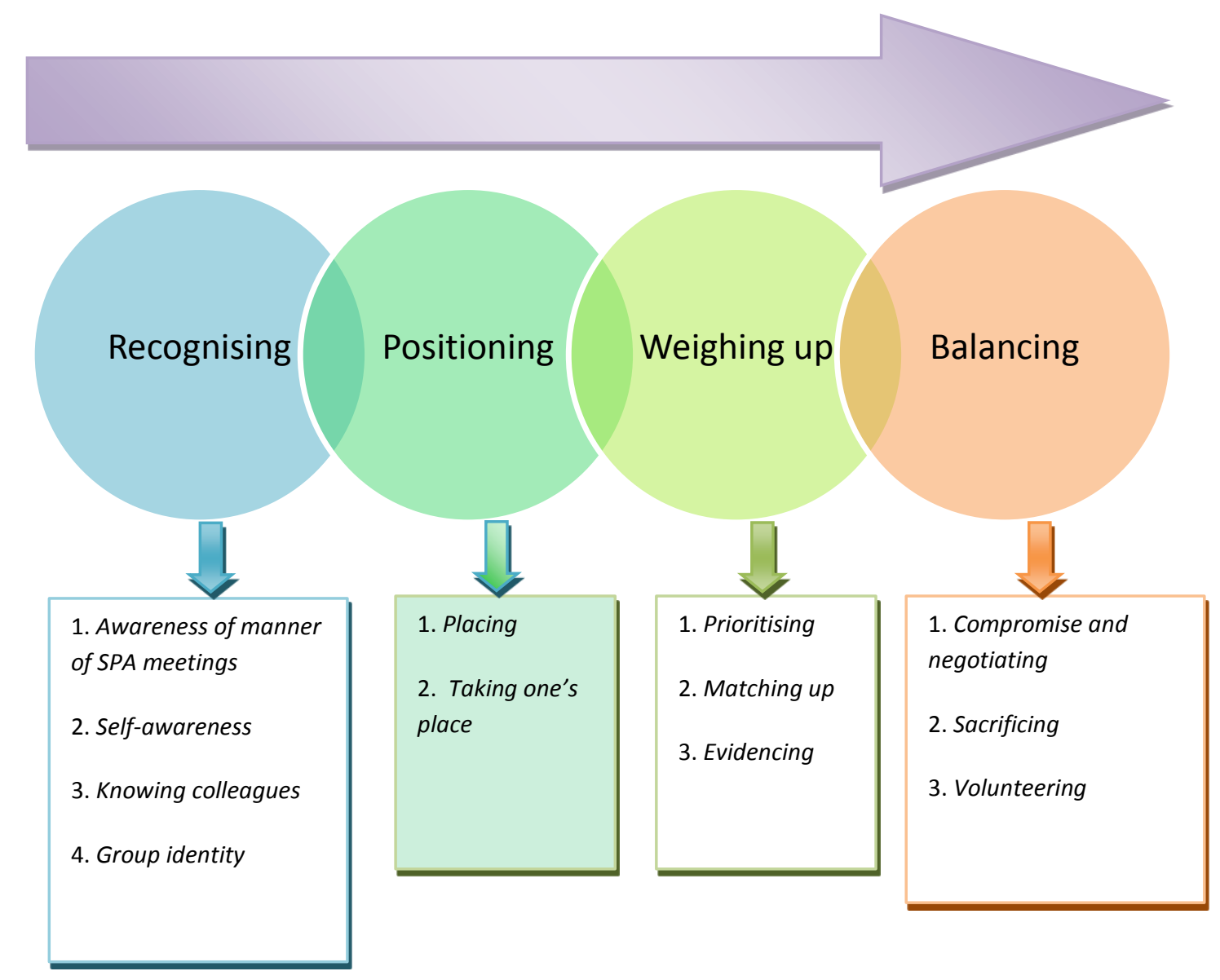

Figure 1: Handling Role Boundaries phases and sub-phases 
Disclosures made during interviews revealed that participants saw the purpose of the SPA meeting and their attendance was to make decisions. This had evolved over time to become a routine and ideal system to deal with referrals:

'As a system of dealing with incoming referrals quite effectively, I think it works... we will discuss and decide what needs to be done and hopefully come to a consensus on that...' (Consultant psychiatrist, male, area 6).

'So we conduct this, you know what can be seen as a triage or a sorting process' (Consultant psychiatrist, male, area 1).

'Ideally the single point of access meeting is the first forum through which referrals to the CMHT are discussed... the process is to just find the best pathway for each individual referral' (Team lead, male, area 3).

'We've built that system up over the years since we started and I think it works pretty well' (Nurse, female, area 4).

Constant comparative analysis gradually revealed the theory explaining how SPA meeting attendees do work together to make decisions about clients in the meeting. Such analysis involves comparing data line by line and incident (occurrences in the field) by incident, and coding the data with categories that sum up ideas about the data. The eventual theory consists of categories integrated together (Artinian and West 2009). These categories are key words resulting from analysing field notes that describe prominent ideas, themes and phenomena present in the data. There are different levels of categories. The core category represents the highest-level concept of the theory relating to the other categories (Giske and Artinian 2009 ). To be the highest level, the core category must be able to provide an overview of how participants resolve their main concern. Categories linking most closely to this core category become concepts of the theory. The overall theory is a set of grounded concepts arranged around a core category, integrated as a parsimonious theory (Glaser 1978 ). The core category of handling role boundaries is also known as a basic social process, since it emerged in a field where participants are moving through a situation (Glaser 1996, Artinian 2009 ). SPA meeting attendees are moving through a decision-making period that starts from hearing about a client and ends with making a decision about that client.

Theoretical sampling is a grounded theory strategy used by allowing the data and developing categories to indicate which avenues and data collection should be pursued to 
develop the theory further (Glaser and Strauss 1967, Glaser 1978 , Giske and Artinian 2009 ). This guides the researcher to further establish and/or discard categories and their properties (Bryant and Charmaz 2010 ). In this study, theoretical sampling indicated when observations should be suspended and interviews needed to be sought. Twenty four meeting observations and eight in-depth interviews with attendees were carried out before data saturation was achieved in searching for the resolution of the main concern. Data saturation is the point at which the data are not revealing anything new and categories can no longer be expanded (Glaser 1978).

\section{Findings}

Handling role boundaries considers the range of roles present in SPA meetings. On first impressions, this might present itself in the form of different professional backgrounds. However, the basic social process takes into account the multiple roles inherent in one person; for example, their allegiance to a CMHT, or their group identity, their personality traits, as well as their professional identity. All these roles have associated boundaries that revolve around the most one will do and the limits; for example, strengths and capabilities, limitations, role 'norms' and tendencies. Attendees of SPA meetings need to employ strategies for dealing with these different roles and their related boundaries so that they can make a decision for all clients who have been processed for discussion.

The four main variables (Figure 1) can be seen as 'phases' and can be linked back to empirical incidents, recorded in the data, to show how they have emerged through what is known as the concept-indicator model (Holton 2010). This ensures that all concepts have empirical evidence to support them (Bryant and Charmaz 2010) and also means that concepts have earned their way into the theory (Holton 2010). The handling role boundaries process comprises four phases: recognising, positioning, weighing up and balancing. Each of these phases leads to the next in a systematic and necessary manner. For example, the positioning phase cannot take place if the recognising phase has not done so, and so on in sequence. The essence of this theory is set out in Table 1. 


\begin{tabular}{|c|c|c|}
\hline Phase & Description & Related quotations \\
\hline 1. Recognising & $\begin{array}{l}\text { Recognising the different role } \\
\text { boundaries is important for attendees } \\
\text { in their endeavour to plan for each } \\
\text { client during the meeting }\end{array}$ & $\begin{array}{l}\text { Knowing one's colleagues } \\
\text { "By working closely ... kind of know } \\
\text { where we're all coming from ... from } \\
\text { my point of aspect, it's actually very } \\
\text { helpful because you do get a sense of } \\
\text { where the team are at as well in } \\
\text { terms of how many people they can } \\
\text { see...You also get an understanding of } \\
\text { the social care assessment process } \\
\text { which is a mystery to most medics I } \\
\text { have to say..." (Consultant } \\
\text { Psychiatrist, Male, Area 1) }\end{array}$ \\
\hline 2. Positioning & $\begin{array}{l}\text { Positioning helps attendees to } \\
\text { establish expectations they have of } \\
\text { themselves and others and also sees } \\
\text { them taking their place to behave in } \\
\text { certain ways during the meeting }\end{array}$ & $\begin{array}{l}\text { Taking one's place } \\
\text { "...there's a place for my opinion, my } \\
\text { subjective opinion, but not for that to } \\
\text { be the basis of the decision. Decision- } \\
\text { making needs to be across the } \\
\text { board..." (Consultant Psychiatrist, } \\
\text { Female, Area 5) }\end{array}$ \\
\hline 3. Weighing Up & $\begin{array}{l}\text { Attendees weigh up the contributions } \\
\text { and conceptions that came as a } \\
\text { consequent of the Positioning sub- } \\
\text { stages }\end{array}$ & $\begin{array}{l}\text { Prioritising } \\
\text { "...it's a question of actually taking it } \\
\text { on face value and actually saying } \\
\text { "Well yeah, it's been referred to Dr } \\
* * * * * * * \text { but it it's more appropriate to } \\
\text { go to IAPT because that's the nature } \\
\text { of the issue that's in the letter..." } \\
\text { (Team Lead Male, Area } 3 \text { ) }\end{array}$ \\
\hline 4. Balancing & $\begin{array}{l}\text { Attendees negotiate a balance which } \\
\text { takes into account the main role } \\
\text { boundaries present in the meeting. }\end{array}$ & $\begin{array}{l}\text { Sacrificing } \\
\text { "So even if I thought to myself "Well I } \\
\text { actually think I could see that person" } \\
\text {... think medically you keep away } \\
\text { because it would cause problems. I'd } \\
\text { bow down to her (colleague), if she } \\
\text { had a really strong view about that, } \\
\text { there's no question. Even if I had } \\
\text { quite a strong view, I would kind of } \\
\text { go with her" (Consultant Psychiatrist. } \\
\text { Male, Area 6) }\end{array}$ \\
\hline
\end{tabular}

Table 1: Basic model of Handling Role Boundaries

\section{Discussion}

The recognising phase establishes awareness of oneself, one's colleagues, one's group and the SPA meeting process and tendencies, which guides attendees on the best approaches to follow subsequently. Without this initial phase of recognising, with its subcategories, attendees could not establish expectations of themselves and others in the multidisciplinary environment hosted by the SPA meeting. For example, by recognising that a SPA meeting works with everyone reading letters, attendees are able to enter the positioning phase knowing that they will need to read a letter and that this will be done in a certain order. Essentially, the positioning phase relies on awareness acquired from recognising. 
The positioning phase is important because it signals the start of attendees working with the role boundaries they have become aware of and gives them direction. Forming expectations is important because in this multidisciplinary atmosphere no one person can do everything, so they learn to rely on people's skills and strengths. Moreover, it helps them on a personal level to determine what they need to do in the meeting and what they can leave for other people. In the development of the discussion, the positioning phase gives the opportunity for conceptions of clients to be formed and contributions to be made. This paves the way for the next phase of the process weighing up.

Weighing up is integral to moving on the decision-making process. For the clients whose problems are complex, discussions are longer and the phase of weighing up provides an accurate way of explaining the conversation content of attendees and their motivations. The three sub-categories of weighing up can be employed to justify why a certain intervention may be appropriate, or to provide a reason why it may not be. Narrowing down the options makes the elements that decisions are based on more manageable, which works with the time constraints of SPA meetings. The effects of weighing up also allow attendees to move on to the balancing phase, which completes decision making for clients in the context of the meeting. For clients with less complex problems, the main concern is often resolved through the weighing up phase. However, with cases that require longer discussion and have less clarity, the balancing phase becomes crucial.

Balancing is most pertinent when clients' problems are complex and there may be several or no ideal indications as to what might be best for them. When one considers the main concern being investigated and its need to be resolved in the meeting, it is clear to see why the balancing phase may be needed. Balancing logically follows the previous phases and takes into account what has emerged from them. It demonstrates the last stage of strategies that attendees employ to work together, taking on board all contributions to balance the role boundaries to reach a decision together about where to place the client.

The Glaserian grounded theory approach indicates that once one's theory has been sufficiently developed, a focused literature review can then proceed, revolving around 
the core and related categories of the theory (Glaser 1978, Heath 2006, Glaser 2007). Facets of identity, including personality and professional identity described by handling role boundaries, need to be understood within the larger sociological concepts of identity, self, interaction and roles.

\section{Identity, self, interaction and roles}

Stets and Burke (2005) offer a useful review of the sociological literature of self and identity. These authors present Stryker's (1980) work which uses a structural approach to the symbolic interactionist perspective. Stryker suggests that societies are stable and challenges the traditional symbolic interactionist approach (Mead 1934) by opposing the notion of individuals being free to define situations in any way they wish. According to the structural symbolic interactionist thesis, there are patterned 'norms' that represent regular ways of doing things through human action (Stryker 1980). Stets and Burke (2005) support this standpoint claiming that:

'Individuals act, but those actions exist within the context of the full set of patterns of action, interaction and resource transfers among all persons, all of which constitute the structure of society.'

Self and society are reciprocal, and social structures are generated from human agency (such actions become patterns over time), but individual actions need to be understood in the context of the social structures where such actions take place (Stets and Burke 2005). With regard to the handling role boundaries theory, this would account for behaviours of SPA meeting attendees by justifying the balancing phase. There are choices available to attendees as they embark on acting in certain ways, but this choice is limited in the context of the meeting and the need to make decisions together about clients. Thus, individual actions in SPA meetings reflect the context in which they take place and beyond this, for example, the wider context of the NHS organisation.

Since at the heart of the handling role boundaries theory is the term 'role', it is useful to explore its treatment theoretically and how this resonates with the author's intentions to use it. The nature of role theory has led to much confusion due to its early proponents applying the term in different ways (Biddle 1986). However, Biddle (1986) maintains that it offers integral theoretical understanding into a key element of social life: 'It explains roles by presuming that persons are members of social positions and hold 
expectations for their own behaviours and those of other persons.' Stryker and Burke (2000) suggest that social roles relate to expectations that are associated with certain positions present in networks of relationships. The theory of handling role boundaries extensively advocates these definitions and shares such assumptions about social beings, such as attendees of SPA meetings. These social positions may be formally defined, as with professional roles, or have a more informal status, such as the traits of one's personality. Handling role boundaries maintains that such role aspects of identities do not always manifest separately and are not always competing for prominence. They are capable of merging and therefore behaviour observed may be an amalgamation of such roles. Stryker (1980) suggests that multiple role identities need to be organised (Stets and Burke 2005) and describes a salience hierarchy taking place. According to Stets and Burke (2005):

'Whilst the prominence hierarchy of McCall and Simmons addresses what an individual values, the salience hierarchy focuses on how an individual will likely behave in a situation. What one values may or may not be related to how one behaves in a situation, although there is a significant relationship between the two.'

Handling role boundaries embraces this notion of a salience hierarchy as postulated by Stryker (1980). Some SPA meeting attendees admitted in interviews that they knew when it was appropriate to hold back certain views and personal beliefs to bring the decision-making process to an end. This was pertinent in the balancing phase when one may decide to put the collective interests of the group first rather than one's agenda based on personality and/or professional role. One must consider the sanctions and rewards associated with devising a salience hierarchy and proceeding with a particular identity over another. Biddle (1986) suggests that most role theorists concur that humans are socially aware actors who ascertain expectations through experience, and are thus aware of these expectations upon them. There are three main origins of expectations that are referred to: norms, beliefs and preferences. Biddle (1986) argues that all three are capable of contributing to expectations and thus behaviour. These modalities result in roles manifesting for different reasons. Handling role boundaries demonstrates how all three contribute to behaviour. 'Norms' in SPA meetings have been established over time by actions evolving into patterned regularities and forming established conventions. Participants also disclosed their beliefs and preferences as motivated by their work role - for example, as social worker - which did not always 
comply with their general role as a CMHT member. This was something the field terms as 'role conflict'.

The basic social process gives prominent attention to the effect of personality roles, something that is scarce in the sociological and multidisciplinary literature (Ebbs and Timmons 2008). According to Peck (2003), CMHT conflicts often revolve around competing disciplines in one physical space and sometimes these professional boundaries can translate into barriers to effective working:

'Boundaries come into being through differences in organisational structures and values... they are inculcated into individuals through training regimes and sustained patterns of socialisation.'

Handling role boundaries rests on the assumption that personality boundaries also evolve in the way that Peck (2003) describes for professional boundaries, which is why they need to be given as much attention. Although conflicts may arise from the amalgamation of these various boundaries in the SPA meeting, attendees need to find resolution because they have a specific aim. This is where the basic social process comes into fruition. Peck (2003) agrees that when teams have shared aims they work more effectively together.

The emergence of both professional and personality traits in SPA meetings can also be understood sociologically. Drawing on Goffman's 1959 work on impression management and the presentation of self in everyday life, the theatrical analogy that he uses can be applied to SPA meetings. According to Goffman (1959), social life consists of front regions and back regions; the former allows space for formal roles while the latter provides freedom to shed the constraints of such roles and assume informal identities. The meetings could be construed as a 'backstage' from the clinical encounters the professionals engage in. There were informalities in the meetings, including the language used; on some occasions a light-hearted manner reverberated with joking and laughter. However, although there were times when attendees' personality traits emerged and thus needed to be handled, the meetings also reflected some behaviour that Goffman would designate as front region behaviour. For example, there was a formal agenda, which in the context of the main concern required subjects to maintain their clinical roles. Designating the SPA meeting in terms of regions may not be as easily applicable 
since it is difficult to define with precision attendees' behaviour as formal or informal. This shows that SPA meetings are a complex decision-making forum where various aspects of identity can be accommodated and helps in the understanding of how the theory of handling role boundaries captures the importance of both professional and personality roles in decision making. Handling role boundaries as a theory clearly finds resonance with extant sociological themes and literature. The innovative theory explains how personality traits can, and do, contribute to meeting discussions that were designed to draw on professional capacities. Using extant literature as further data has allowed handling role boundaries to be compared and understood alongside key sociological tenets, thus contributing to the knowledge base, while also providing insight into the research question.

\section{Conclusion}

This article has presented an emergent grounded theory called handling role boundaries and described how the integrated concepts form a process used by mental health professionals to make decisions about clients. The four phases have been discussed with key sociological themes of identity, self, interaction and roles. Handling role boundaries finds resonance with structural symbolic interactionism and Biddle's (1986) interpretation of role theory. The comparison of handling role boundary concepts to sociological literature further strengthens the theory's ability to show how, and why, personality traits emerge in the substantive area.

\section{Implications for practice}

Handling role boundaries:

- Allows meeting attendees to identify what works well in their decision making

- As a basic social process, offers new insight into this practical clinical decision making behaviour, including the contribution of personality traits

- As a conceptual model about decision making, may help identify how decisions about clients can be improved

In addition, attendees of single point access meetings need to employ strategies for dealing with different roles and their related boundaries so that they can make a decision for the benefit of the client. 


\section{Acknowledgements}

The author would like to thank all the participants who took part in the research study, and $\mathrm{Dr}$ Hugh Middleton and Professor Ian Shaw at the University of Nottingham who provided supervisory support for the research.

\section{References}

Artinian B (1998) Grounded theory research: its value for nursing. Nursing Science Quarterly. 11, 1, 5-6.

Artinian B (2009) Gerund mode: basic social process. In Artinian B, Giske T, Cone P (Eds) Glaserian Grounded Theory in Nursing Research: Trusting Emergence. Springer, New York NY.

Artinian B, West K (2009) Conceptual mapping as an aid to grounded theory development. In Artinian B, Giske T, Cone P (Eds) Glaserian Grounded Theory in Nursing Research: Trusting Emergence. Springer, New York NY.

Beck U (1992) Risk Society. Towards a New Modernity. SAGE Publications Ltd, London.

Becker H (1963) Outsiders. Studies in the Sociology of Deviance. The Free Press, New York NY.

Biddle B (1986) Recent developments in role theory. Annual Review of Sociology. 12, 1, 67-92.

Bryant A, Charmaz K (2010) (Eds) The SAGE Handbook of Grounded Theory. Paperback edition. Sage, London. 
Cone P, Artinian B (2009) Bending the directives of Glaserian grounded theory

in nursing research. In Artinian B, Giske T, Cone P (Eds) Glaserian Grounded Theory in Nursing Research: Trusting Emergence. Springer, New York NY.

Eaton W (2001) The Sociology of Mental Disorders. Third edition. Praeger, London.

Ebbs N, Timmons S (2008) Inter-professional working in the RAF Critical Care Air Support Team (CCAST). Intensive \& Critical Care Nursing: the Official Journal of the British Association of Critical Care Nurses. 24, 1, 51-58.

Erikson K (1966) Wayward Puritans: A Study in the Sociology of Deviance. Wiley, New York NY.

Giddens A (2009) Sociology. Sixth edition. Polity Press, Cambridge.

Giske T, Artinian B (2009) Learning Glaserian grounded theory by doing it. In Artinian B,

Giske T, Cone P (Eds) Glaserian Grounded Theory in Nursing Research: Trusting Emergence. Springer, New York NY.

Glaser B (1978) Theoretical Sensitivity: Advances in the Methodology of Grounded Theory. Sociology Press, Mill Valley CA.

Glaser B (Ed) (1996) Gerund Grounded Theory: The Basic Social Process Dissertation. Sociology Press, Mill Valley CA.

Glaser B (1998) Doing Grounded Theory: Issues and Discussions. Sociology Press, Mill Valley CA. 
Glaser B (2007) All is data. The Grounded Theory Review: An International Journal. 6, 2, $1-22$.

Glaser B, Strauss A (1967) The Discovery of Grounded Theory: Strategies for Qualitative Research. Aldine Publishing, Hawthorne NY.

Goffman E (1959) The Presentation of Self in Everyday Life. Doubleday, Garden City NY.

Heath $\mathrm{H}$ (2006) Exploring the influences and use of the literature during a grounded theory study. Journal of Research in Nursing. 11, 6, 519-528.

Hewitt J (2008) Dangerousness and mental health policy. Journal of Psychiatric and Mental Health Nursing. 15, 3, 186-194.

Holton J (2010) The coding process and its challenges. In Bryant A, Charmaz K (2010) (Eds) The Sage Handbook of Grounded Theory. Sage, London.

Lucas H, Scammell A, Hagelskamp C (2005) How do GP registrars feel about dealing with mental health issues in the primary care setting? A qualitative investigation. Primary Health Care Research and Development. 6, 1, 60-71.

McCall G, Simmons J (1978) Identities and Interactions. Free Press, New York NY.

Mead G (1934) Mind, Self, \& Society from the Standpoint of a Social Behaviorist. The University of Chicago Press, Chicago IL.

Oxford Dictionaries (2015) www.oxforddictionaries.com/definition/english/behaviour 
(Last accessed: February 29 2016.)

Peck E (2003) Working in multidisciplinary community teams. In Hannigan B, Coffey M (Eds) The Handbook of Community Mental Health Nursing. Routledge, Oxford.

Read J (2005) The bio-bio-bio model of madness. The Psychologist. 18, 10, 596-597.

Rogers A, Pilgrim D (2005) A Sociology of Mental Health and Illness. Third edition. Open University Press, Maidenhead.

Stets J, Burke P (2005) A sociological approach to self and identity. In Leary M, Tangney (Eds) Handbook of Self and Identity. Guilford Press, New York NY.

Stryker S (1980) Symbolic Interactionism: A Social Structural Version. Benjamin/ Cummings, Menlo Park CA.

Stryker S, Burke P (2000) The past, present, and future of an identity theory. Social Psychology Quarterly. 63, 4, 284-297.

Turner T, Colombo A (2008) Risk. In Tummey R, Turner T (Eds) Critical Issues in Mental Health. Palgrave Macmillan, Basingstoke. 